\title{
Impact of Pseudomonas aeruginosa Infection on Respiratory Muscle Function in Adult Cystic Fibrosis Patients
}

\author{
Friederike Sophie Magnet ${ }^{a}$ Jens Callegari ${ }^{a}$ Doris Dieninghoff ${ }^{a}$ \\ Marc Spielmanns $^{b}$ Jan Hendrik Storre ${ }^{a, c}$ Claudia Schmoor $^{d}$ \\ Wolfram Windisch ${ }^{\mathrm{a}}$ \\ a Department of Pneumology, Cologne Merheim Hospital, Kliniken der Stadt Köln gGmbH, Faculty of Health/ \\ School of Medicine, Witten/Herdecke University, Cologne, b' St. Remigius Krankenhaus Opladen, Leverkusen, and \\ 'Department of Pneumology and d Clinical Trials Unit, University Medical Center Freiburg, Faculty of Medicine, \\ University of Freiburg, Freiburg, Germany
}

\section{Keywords}

Cystic fibrosis · Pseudomonas aeruginosa $\cdot$ Respiratory muscle function · Respiratory muscle physiopathology ·

Quality of Life

\begin{abstract}
Background: Pseudomonas aeruginosa infection impairs respiratory muscle function in adolescents with cystic fibrosis, but its impact on adult patients has not been characterised. Objectives: To investigate respiratory muscle function in adult cystic fibrosis patients according to $P$. aeruginosa status (repetitive samples over 12 months). Methods: The pressure-time index of the respiratory muscles ( $\mathrm{PTI} I_{\text {mus }}$ ), a measure of their efficiency, served as the primary outcome. In addition, respiratory load and maximal respiratory muscle strength were assessed. Results: In 51 patients examined ( $65 \%$ female; median age 32 years, IQR 24-40), a median of 3.0 (IQR 2-4) different pathogens was found in each patient. The $\mathrm{PTI}_{\text {mus }}$ was 0.113 and 0.126 in Pseudomonas-positive $(n=33)$ and -negative $(n=18)$ patients, respectively $(p=0.53)$. Univariate analysis showed a lower $\mathrm{PTI}_{\text {mus }}$ in male than in female patients $(p=0.006)$. Respiratory muscle load
\end{abstract}

(c) 2016 S. Karger AG, Basel

E-Mail karger@karger.com www.karger.com/res and strength were otherwise comparable, with the exception of higher nasal sniff pressures in Pseudomonas-positive patients who were chronically infected $(>50 \%$ of positive samples). Quality of Life (according to the Cystic Fibrosis Questionnaire-Revised) was higher if both respiratory load and the $\mathrm{PTI}$ mus were low (high respiratory muscle efficiency). Conclusions: Chronic $P$. aeruginosa infection does not influence respiratory muscle efficiency in adult cystic fibrosis patients with otherwise multiple co-infections. In addition, patients with reduced respiratory muscle efficiency had worse Quality of Life.

(c) 2016 S. Karger AG, Basel

\section{Introduction}

The median life expectancy in cystic fibrosis $(\mathrm{CF}) \mathrm{pa}-$ tients has increased in the last decades and is estimated to be $>50$ years in children who were born after the year 2000 [1]. However, Pseudomonas aeruginosa infection in CF patients remains a major problem, with a negative impact both on overall survival and Quality of Life (QoL) [2-4].
Prof. Dr. Wolfram Windisch

Department of Pneumology, Cologne Merheim Hospital, Kliniken der Stadt Köln gGmbH, Faculty of Health/School of Medicine, Witten/Herdecke University Ostmerheimer Strasse 200, DE-51109 Köln (Germany)

E-Mail windischw@kliniken-koeln.de 
In this regard, respiratory disturbances related to $P$. aeruginosa infection are a major predictor of morbidity and mortality amongst CF patients [3]. These disturbances may affect the lungs, as well as respiratory mechanics, where the presence of both conditions can contribute to dyspnoea and may ultimately lead to respiratory failure. Furthermore, chronic $P$. aeruginosa infection and high IgG levels were shown to be associated with a decline in exercise capacity in adolescent patients with CF [5], and a decreased exercise capacity is found in a relevant proportion of patients with CF [6]. Despite the link between $P$. aeruginosa infection and respiratory disturbances, respiratory mechanics are rarely investigated in CF patients. In general, the load imposed on the respiratory muscles, respiratory muscle efficiency, and respiratory muscle strength are all key factors in determining respiratory mechanics [7]. In particular, the impact of P. aeruginosa infection on respiratory mechanics is not fully understood, but it is suggested to be clinically important, since chronic infection has been shown to impair respiratory muscle function [8]. Importantly, an animal study showed that CF mice with sustained infection with $P$. aeruginosa had a reduced diaphragmatic force-generating capacity [9]. Furthermore, a detailed study on the impact of $P$. aeruginosa infection on respiratory mechanics in adolescent CF patients clearly showed that $P$. aeruginosa infection can indeed have an independent effect on respiratory muscle function [7].

However, the findings reported in that study are only valid for adolescents, since the median age of the subjects was 13 years (IQR 10-17). In contrast to their younger counterparts, adult CF patients have (1) different as well as additional co-morbidities, (2) a longer disease duration, and (3) co-existing infections. Therefore, the impact of $P$. aeruginosa infection on respiratory muscle function needs to be elucidated specifically for adult patients. As a consequence, the present study aimed to carry out a detailed characterisation of respiratory muscle function in adult CF patients while simultaneously investigating the impact of $P$. aeruginosa infection on respiratory mechanics.

\section{Patients and Methods}

The study protocol was approved by the Ethics Committee at Witten/Herdecke University, Witten, Germany, and was undertaken at the Department of Pneumology of the Lung Clinic, Cologne Merheim Hospital, Witten/Herdecke University, Cologne, Germany. The study was performed in accordance with the ethical standards laid down in the Declaration of Helsinki (last revision from October 2013). The study was registered at the German Clinical Trials Register (DRKS00008786). Informed written consent was obtained from all subjects.

\section{Patients}

Adult outpatients ( $\geq 18$ years of age) with an established diagnosis of CF according to guidelines [10] were included in the study. All subjects were in a stable disease state. Patients were excluded from the study if any of the following criteria were met:

- Pulmonary exacerbation (as previously defined [11]), with or without hospitalisation, within 30 days of study uptake

- Hospitalisation due to any cause other than exacerbation within 30 days of study uptake

- Administration of intravenous antibiotics within 30 days of study uptake

- Status post lung transplantation

\section{Respiratory Muscle Assessment, Lung Function Testing, and}

Exercise Capacity Assessment

Respiratory muscle function parameters were assessed using the ZAN 100 (nSpire, Oberthulba, Germany). Specifically, the following measurements were performed: nasal sniff pressures $\left(\mathrm{Sn}_{\mathrm{Pna}}\right)$; the pressure generated in the first $100 \mathrm{~ms}$ of inspiration against an occluded airway during quiet breathing $\left(\mathrm{P}_{0.1}\right)$; maximum inspiratory mouth occlusion pressure $\left(\mathrm{PI}_{\max }\right)$; maximum expiratory mouth occlusion pressure $\left(\mathrm{PE}_{\max }\right)$; tidal volume (TV); breathing frequency $(\mathrm{Bf})$; minute ventilation; total cycling time $\left(\mathrm{T}_{\text {tot }}\right)$; and inspiratory time $\left(\mathrm{T}_{\mathrm{I}}\right)$. All measurements were performed in accordance with the recent German recommendations for respiratory muscle testing [12], which conform to international guidelines [13]. The only difference pertained to the measurement of $\mathrm{PI}_{\max }$, which was assessed as peak pressure at residual volume. Importantly, previous research has clearly shown that this is a comparable, reliable approach to the assessment of inspiratory muscle strength when compared to plateau pressures obtained according to international guidelines [14].

From these measurements, the following calculations were performed: respiratory capacity $\left(\mathrm{P}_{0.1} / \mathrm{PI}_{\max }\right)$ and specific inspiratory impedance $\left(\mathrm{P}_{0.1} \times \mathrm{T}_{\mathrm{I}} / \mathrm{TV}\right)$, where each served as a surrogate for respiratory load, and airway pressure during inspiration $\left(\mathrm{P}_{\mathrm{I}}\right)=5 \times$ $\mathrm{P}_{0.1} \times \mathrm{T}_{\mathrm{I}}$ [15-17]. Finally, the pressure-time index of the respiratory muscles $\left(\mathrm{PTI}_{\mathrm{mus}}\right)$ was calculated as follows: $\mathrm{PTI}_{\text {mus }}=($ mean $\left.\mathrm{P}_{\mathrm{I}} / \mathrm{PI}_{\max }\right) \times\left(\mathrm{T}_{\mathrm{I}} / \mathrm{T}_{\text {tot }}\right) . \mathrm{PTI}_{\mathrm{mus}}$ is suggested to represent the balance between neuromuscular competence and respiratory load, as well as the efficiency of the respiratory muscles $[7,15,16]$. In this regard, a higher $\mathrm{PTI}_{\text {mus }}$ indicates ineffective or limited respiratory muscle function, and is associated with a higher risk of respiratory muscle fatigue $[7,17]$.

Lung function parameters were assessed in accordance with international guidelines (spirometry and full body plethysmography; ZAN 500; nSpire) [18-22]. In addition, the standardised 6-min walk test (6MWT) was performed according to previous recommendations $[23,24]$. Here, capillary blood gas analysis was additionally performed prior to and directly after walking [25].

\section{QoL Measurements}

QoL was assessed using the Cystic Fibrosis QuestionnaireRevised (CFQ-R) [26, 27]. The CFQ-R contains 12 domains (scores ranging from 0 to 100), where higher scores represent a better QoL. For further analysis, 4 of the 12 subscales suitable according to the 
Table 1. Demographic and quality-of-life data (CFQ-R) for the 8 infection status groups

\begin{tabular}{lcccc}
\hline & Group 1 $(n=13)$ & Group 2 $(n=5)$ & Group 3 $(n=5)$ & Group 4 $(n=28)$ \\
\hline Male, $n(\%)$ & $3(23.1)$ & $2(40.0)$ & $1(20.0)$ & $12(42.9)$ \\
BMI & $24.7(21.1-26.5)$ & $22.2(19.6-22.3)$ & $20.2(18.1-21.7)$ & $21.7(19.7-23.9)$ \\
Age, years & $27.0(23.0-35.0)$ & $30.0(25.0-37.0)$ & $32.0(30.0-32.0)$ & $32.5(25.0-46.0)$ \\
CFQ-R subscale score & $70.8(57.1-95.8)$ & $87.5(75.0-95.8)$ & $91.7(79.2-91.7)$ & $81.3(62.5-87.5)$ \\
$\quad \begin{array}{l}\text { Physical functioning } \\
\text { Respiratory symptoms }\end{array}$ & $72.2(61.1-83.3)$ & $61.1(50.0-66.7)$ & $61.1(44.4-77.8)$ & $61.1(54.4-75.6)$ \\
$\quad$ Health perception & $66.7(55.6-88.9)$ & $66.7(55.6-77.8)$ & $66.7(55.6-77.8)$ & $66.7(55.6-88.9)$ \\
$\quad$ Treatment burden & $55.6(33.3-77.8)$ & $66.7(44.4-66.7)$ & $66.7(44.4-88.9)$ & $66.7(55.6-77.8)$ \\
\hline & Group A $(n=18)$ & Group B (n=33) & Group C $(n=23)$ & Group D (n=28) \\
\hline $\begin{array}{l}\text { Male, } n \text { (\%) } \\
\text { BMI }\end{array}$ & $5(27.8)$ & $13(39.4)$ & $6(26.1)$ & $12(42.9)$ \\
Age, years & $22.6(20.7-25.5)$ & $21.6(19.7-23.6)$ & $22.1(19.6-25.1)$ & $21.7(19.7-23.9)$ \\
CFQ-R subscale score & $28.5(24.0-37.0)$ & $32.0(26.0-40.0)$ & $30.0(24.0-37.0)$ & $32.5(25.0-46.0)$ \\
$\quad \begin{array}{l}\text { Physical functioning } \\
\text { Respiratory symptoms }\end{array}$ & $81.3(58.3-95.8)$ & $83.3(66.7-91.7)$ & $87.5(58.3-95.8)$ & $81.3(62.5-87.5)$ \\
Health perception & $69.5(50.0-83.3)$ & $61.1(53.3-77.8)$ & $66.7(50.0-77.8)$ & $61.1(54.4-75.6)$ \\
Treatment burden & $66.7(55.6-88.9)$ & $66.7(55.6-88.9)$ & $66.7(55.6-88.9)$ & $66.7(55.6-88.9)$ \\
\hline
\end{tabular}

Values are indicated as median (and IQR). Groups according to Pseudomonas aeruginosa status (Leeds criteria [29]): group 1 = never infected; group 2 = free of infection; group 3 = intermittently infected; group $4=$ chronically infected. Group $\mathrm{A}=$ comprising groups 1 and 2 ( $P$. aeruginosa negative); group $\mathrm{B}=$ comprising groups 3 and 4 ( $P$. aeruginosa positive); group $\mathrm{C}=$ comprising groups 1,2 , and 3 (not chronically infected with $P$. aeruginosa); group $\mathrm{D}=$ comprising group 4 (chronically infected with $P$. aeruginosa). CFQ-R, Cystic Fibrosis Questionnaire-Revised; IQR, interquartile range.

content of the subscale were used to determine the effect of $P$. aeruginosa infection on respiratory muscle function: treatment burden, health perception, physical functioning, and respiratory symptoms.

\section{Study Design}

Patients were recruited during a routine outpatient visit. QoL was assessed first, followed by blood gas measurements during rest. Next, lung function and respiratory muscle function were assessed. Finally, the 6MWT was performed.

For microbiological assessment, sputum from expectorating patients was used. If patients could not sufficiently produce sputum, a deep cough swab was used [28]. Samples were collected in sterile disposable tubes, stored at room temperature, and then inoculated and incubated for 10 days for further analysis. For additional classification, both the current microbiological samples and all available past samples were analysed. As clinical routine, microbiological samples were taken at least every 12 weeks.

\section{Classification of $\mathrm{P}$. aeruginosa Infection Status}

The Leeds criteria were used to classify $P$. aeruginosa infection status [29]. Accordingly, patients were classified as (1) "never infected" if $P$. aeruginosa had never been cultured (group 1), (2) "free of infection" if the samples were negative for $\geq 12$ months following a positive culture test (group 2), (3) "intermittently infected" if $\leq 50 \%$ of the samples were positive for P. aeruginosa (group 3 ), and (4) "chronically infected" if $>50 \%$ of the samples were positive for $P$. aeruginosa (group 4).
For the final analysis, group A (comprising groups 1 and 2; "P. aeruginosa negative") was compared to group B (comprising groups 3 and 4; "P. aeruginosa positive"). Furthermore, in a different analysis, group C (comprising groups 1,2, and 3; "not chronically infected with $P$. aeruginosa") was compared to group D (comprising group 4; "chronically infected with P. aeruginosa").

\section{Statistical Analysis}

The primary objective of the study was to compare groups A and B (see Classification of $P$. aeruginosa Infection Status) with respect to the primary endpoint $\mathrm{PTI}_{\text {mus }}$, and to investigate whether $P$. aeruginosa infection status affected respiratory muscle function in adult CF patients. About 50 patients were screened for recruitment, and we assumed they would divide equally into 2 groups. Based on previous work by Dassios et al. [7], a normal distribution was assumed for $\mathrm{PTI}_{\text {mus }}$, with a standard deviation (SD) of 0.06 . Therefore, the study had a power of $80 \%$ to detect a difference in $\mathrm{PTI}_{\text {mus }}$ according to the status of $P$. aeruginosa infection, with a 2 -sided significance level $\alpha$ of $5 \%$ if the difference was 0.05 . This difference was assumed to be clinically relevant and realistic.

A 2-sided $t$ test was performed at a 2-sided a level of $5 \%$, and the difference between groups was calculated with a 95\% confidence interval (CI). Furthermore, the influence of $P$. aeruginosa infection status on $\mathrm{PTI}_{\text {mus }}$ was examined in a linear regression model, in which other baseline factors with influences on $\mathrm{PTI}_{\text {mus }}$ were added for adjustment.
44
Respiration 2017;93:42-50 DOI: $10.1159 / 000452893$
Magnet/Callegari/Dieninghoff/

Spielmanns/Storre/Schmoor/Windisch 
Table 2. Pulmonary and respiratory muscle function as well as IgG levels for the 4 infection status groups

\begin{tabular}{|c|c|c|c|c|}
\hline & Group $1(n=13)$ & Group $2(n=5)$ & Group $3(n=5)$ & Group $4(n=28)$ \\
\hline \multicolumn{5}{|l|}{ Lung function } \\
\hline $\mathrm{FEV}_{1}, \%$ pred. & $80(50-90)$ & $71(56-72)$ & $78(48-99)$ & $63(52-73)$ \\
\hline TLC, \%pred. & $98(89-112)$ & $110(99-114)$ & $118(108-122)$ & $108(101-118)$ \\
\hline RV, \%pred. & $137(115-173)$ & $132(84-163)$ & $172(148-249)$ & $164(136-201)$ \\
\hline RV/TLC, \% & $39(36-46)$ & $44(33-44)$ & $37(37-53)$ & $45(38-54)$ \\
\hline $\mathrm{pH}$ & $7.42(7.41-7.43)$ & $7.42(7.41-7.45)$ & $7.41(7.41-7.42)$ & $7.42(7.41-7.43)$ \\
\hline $\mathrm{PaCO}_{2}$ & $36.7(34.2-37.0)$ & $34.8(33.9-36.6)$ & $38.9(34.4-39.8)$ & $36.5(35.3-38.1)$ \\
\hline $\mathrm{PaO}_{2}$ & $83.0(79.2-84.6)$ & $81.9(78.0-84.1)$ & $81.2(72.3-91.2)$ & $77.5(70.5-83.3)$ \\
\hline $\mathrm{HCO}_{3}^{-}$ & $24.1(23.2-24.6)$ & $23.7(22.6-24.8)$ & $24.5(22.8-25.1)$ & $23.9(23.3-24.7)$ \\
\hline $\mathrm{SaO}_{2}$ & $97.0(96.7-97.4)$ & $97.0(96.7-97.3)$ & $96.5(95.7-96.7)$ & $96.3(95.6-97.0)$ \\
\hline \multicolumn{5}{|l|}{$6 \mathrm{MWT}$} \\
\hline \multicolumn{5}{|c|}{ Respiratory muscle function } \\
\hline $\mathrm{PE}_{\max }, \mathrm{kPa}$ & $11.4(8.7-13.2)$ & $10.2(7.6-14.2)$ & $11.0(10.6-11.1)$ & $10.3(8.4-15.1)$ \\
\hline $\mathrm{P}_{0.1} \times \mathrm{T}_{\mathrm{I}} / \mathrm{TV}$ & $0.5(0.4-0.6)$ & $0.5(0.5-0.6)$ & $0.4(0.3-0.6)$ & $0.5(0.5-0.8)$ \\
\hline $\mathrm{PTI}_{\text {mus }}$ & $0.130(0.097-0.150)$ & $0.074(0.044-0.116)$ & $0.083(0.065-0.092)$ & $0.096(0.074-0.156)$ \\
\hline $\mathrm{P}_{0.1} / \mathrm{PI}_{\max }, \%$ & $4(3-5)$ & $2(2-5)$ & $2(2-2)$ & $3(2-6)$ \\
\hline $\mathrm{Sn}_{\text {Pna }}, \mathrm{kPa}$ & $5.2(3.8-6.3)$ & $4.7(2.6-6.3)$ & $4.8(2.8-6.4)$ & $5.8(5.1-8.4)$ \\
\hline \multicolumn{5}{|l|}{ Immunoglobulin } \\
\hline IgG level, g/L & $13.0(11.6-15.8)$ & $12.0(11.9-15.4)$ & $12.9(10.9-13.5)$ & $14.3(12.4-16.8)$ \\
\hline
\end{tabular}

Values are indicated as median (and IQR). $\mathrm{FEV}_{1}$, forced expiratory volume in $1 \mathrm{~s} ; \mathrm{HCO}_{3}^{-}$, bicarbonate; IgG level, level of immunoglobulin $\mathrm{G}$ (normal value 7-16 g/L); IQR, interquartile range; IVC, inspiratory vital capacity; $\mathrm{PaCO}_{2}$, arterial pressure of carbon dioxide; $\mathrm{PaO}_{2}$, arterial pressure of oxygen; $\mathrm{PE}_{\max }$, maximum expiratory mouth occlusion pressure; $\mathrm{PI}_{\text {max }}$, maximum inspiratory mouth occlusion pressure; $\mathrm{PTI}_{\text {mus }}$, pressure-time index of the respiratory muscles; $\mathrm{P}_{0.1}$, decrease in airway pressure at $0.1 \mathrm{~s} ; \mathrm{P}_{0.1} \times \mathrm{T}_{\mathrm{I}} / \mathrm{TV}$, specific inspiratory impedance; $\mathrm{P}_{0.1} / \mathrm{PI}_{\max }$, respiratory capacity; $\mathrm{RV}$, residual volume; $\mathrm{SaO}_{2}$, oxygen saturation; $\mathrm{Sn}_{\mathrm{Pna}}$, nasal sniff pressures; $\mathrm{TLC}$, total lung capacity; 6MWT, standardised 6-min walk test.

Secondary endpoints were lung function assessment, 6MWT $(\mathrm{m})$, respiratory muscle function parameters $\left(\mathrm{PI}_{\max }, \mathrm{PE}_{\max }, \mathrm{P}_{0.1}\right.$, $\mathrm{Sn}_{\mathrm{Pna}}$, respiratory capacity $\left[\mathrm{P}_{0.1} / \mathrm{PI}_{\max }\right]$, and the effective inspiratory impedance $\left.\left[\mathrm{P}_{0.1} \times \mathrm{T}_{\mathrm{I}} / \mathrm{TV}\right]\right)$, and QoL data. Comparisons of the infection status groups with respect to the secondary endpoints were performed with the same methods. Spearman correlation coefficients were calculated to describe the associations between primary and secondary endpoints. All $p$ values of secondary analyses had to be interpreted descriptively.

\section{Results}

Fifty-one patients (33 female $=64.7 \%$ ) were consecutively enrolled in the study from July to November 2015. Their median age, BMI, and percentage-of-predicted (\%pred.) $\mathrm{FEV}_{1}$ was 32 years (IQR 24-40), 22.0 (IQR 19.724.2), and 66\% (IQR 51-83), respectively. There were at least 4 microbiological samples per patient; 9 patients
(17.6\%) had deep cough swabs instead of sputum samples for microbiological assessment, and 4 out of those patients were chronically infected with $P$. aeruginosa (group 4). A total of 36 different pathogens (including bacteria, fungi, and mycobacteria) were found across all microbiological samples of the study population, ranging from 0 to 7 different pathogens per individual patient (median 3.0 per patient, IQR 2-4). The most frequently found pathogen was $P$. aeruginosa $(n=35)$, followed by Staphylococcus aureus $(n=28)$, Candida albicans $(n=27)$, and Aspergillus fumigatus $(n=10)$.

Four out of the 51 patients $(7.8 \%)$ were on systemic steroids with $5 \mathrm{mg}$ prednisolone per day: 2 patients with CF arthropathy and 2 with status post allergic bronchopulmonary aspergillosis.

The demographic and QoL data for the 8 infection status groups are shown in Table 1 . The pulmonary and respiratory muscle function results as well as the IgG levels 


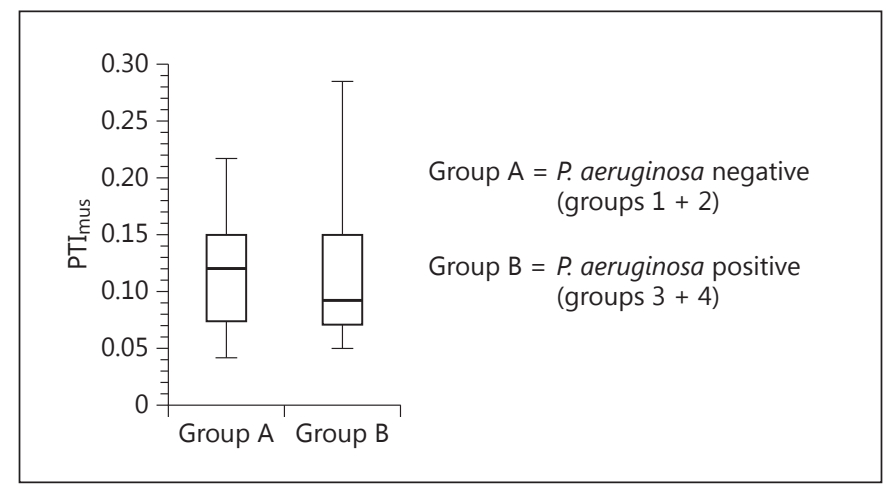

Fig. 1. Pressure-time index of the respiratory muscles $\left(\mathrm{PTI}_{\mathrm{mus}}\right)$. Group A vs. group B.

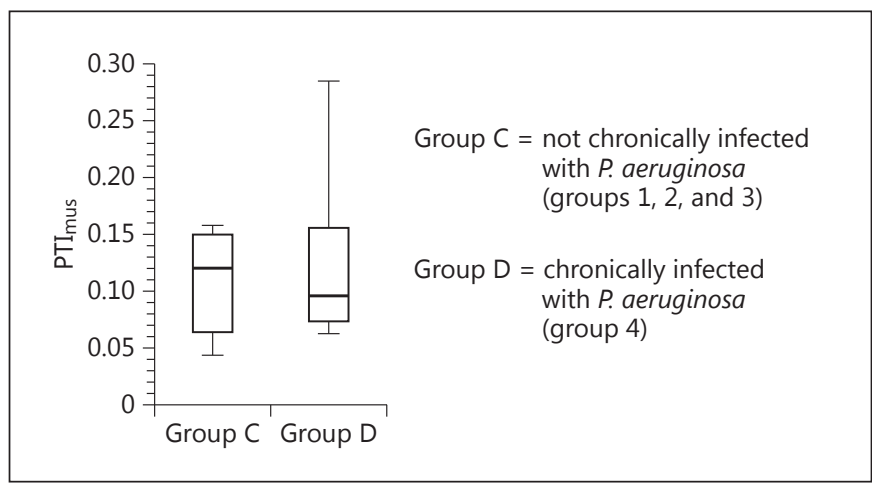

Fig. 2. Pressure-time index of the respiratory muscles $\left(\mathrm{PTI}_{\mathrm{mus}}\right)$. Group C vs. group D.

Table 3. Analysis of the correlation of the $\mathrm{PTI}_{\text {mus }}$ and QoL subdomains with respiratory muscle function parameters, lung function, and exercise capacity

\begin{tabular}{|c|c|c|c|c|c|c|}
\hline & \multicolumn{2}{|l|}{$\mathrm{PTI}_{\text {mus }}$} & \multicolumn{2}{|c|}{$\begin{array}{l}\text { QoL: } \\
\text { physical functioning }\end{array}$} & \multicolumn{2}{|c|}{$\begin{array}{l}\text { QoL: } \\
\text { respiratory symptoms }\end{array}$} \\
\hline & $r$ value & $p$ value & $r$ value & $p$ value & $r$ value & $p$ value \\
\hline QoL: physical functioning & -0.48 & 0.0004 & - & - & 0.63 & $<0.0001$ \\
\hline QoL: respiratory symptoms & -0.42 & 0.002 & 0.63 & $<0.0001$ & - & - \\
\hline $\mathrm{P}_{0.1}$ & 0.68 & $<0.0001$ & -0.45 & 0.0009 & -0.42 & 0.002 \\
\hline $\mathrm{PI}_{\max }$ & -0.57 & $<0.0001$ & 0.36 & 0.009 & 0.27 & 0.055 \\
\hline $\mathrm{PE}_{\max }$ & -0.52 & $<0.0001$ & 0.25 & 0.074 & 0.30 & 0.03 \\
\hline $\mathrm{Sn}_{\text {Pna }}$ & -0.30 & 0.03 & 0.12 & 0.40 & 0.15 & 0.28 \\
\hline $\mathrm{FEV}_{1}$ & -0.34 & 0.016 & 0.48 & 0.0004 & 0.37 & 0.007 \\
\hline $6 \mathrm{MWT}$ & -0.29 & 0.04 & 0.19 & 0.18 & 0.14 & 0.34 \\
\hline
\end{tabular}

$\mathrm{FEV}_{1}$, forced expiratory volume in $1 \mathrm{~s} ; \mathrm{PE}_{\max }$, maximum expiratory mouth occlusion pressure; $\mathrm{PI}_{\text {max }}$, maximum inspiratory mouth occlusion pressure; $\mathrm{PTI}_{\text {mus }}$, pressure-time index of the respiratory muscles; $\mathrm{P}_{0.1}$, decrease in airway pressure at $0.1 \mathrm{~s} ; \mathrm{P}_{0.1} \times \mathrm{T}_{\mathrm{I}} / \mathrm{TV}$, specific inspiratory impedance; $\mathrm{P}_{0.1} / \mathrm{PI}_{\max }$, respiratory capacity; $\mathrm{Sn}_{\mathrm{Pna}}$, nasal sniff pressures; QoL, Quality of Life; 6MWT, standardised 6-min walk test.

are displayed in Table 2. The median dyspnoea (BORG scale) score in the 6MWT was 0 before walking in all groups, and 0 after walking in groups 1,3 , and 4 . Group 2 had a median score of 2 points after walking.

\section{Primary Outcome Parameter $\left(P T I_{\text {mus }}\right)$}

There was no significant difference in $\mathrm{PTI}_{\text {mus }}$ between group A (mean 0.113, SD 0.049) and group B (mean 0.126 , SD 0.080; difference 0.013, 95\% CI [-0.028, 0.055]; $p=0.53$ ) (Fig. 1). Further explorative evaluation showed no difference between group C (mean 0.107, SD 0.047) and group D (mean 0.133, SD 0.084; difference 0.026, $95 \%$ CI $[-0.014,0.065] ; p=0.20$ ) (Fig. 2).
Multivariate analysis investigating the effects of gender, $\mathrm{Sn}_{\text {Pna }}, \mathrm{BMI}, \mathrm{FEV}_{1}$ (\%pred.), TLC (\%pred.), and walking distance $(\mathrm{m})$ showed a lower $\mathrm{PTI}_{\mathrm{mus}}$ in male than in female patients (difference $-0.059,95 \%$ CI $[-0.103,-0.015] ; p=$ $0.010) . \mathrm{Sn}_{\text {Pna }}, \mathrm{BMI}, \mathrm{FEV}_{1}$ (\%pred.), TLC (\%pred.), and walking distance $(\mathrm{m})$ had no influence on $\mathrm{PTI}_{\text {mus }}$.

There was no significant difference in $\mathrm{PTI}_{\mathrm{mus}}$ in regard to normal versus elevated IgG levels (cut-off $>16 \mathrm{~g} / \mathrm{L}$ ) (mean PTI $\mathrm{I}_{\text {mus }} 0.121$ [SD 0.077] vs. 0.124 [SD 0.047]; difference $-0.003,95 \%$ CI $[-0.050,0.042] ; p=0.89)$. In addition, after adjusting for other factors in this multivariate analysis, no difference could be detected between the infection status groups.
46
Magnet/Callegari/Dieninghoff/ Spielmanns/Storre/Schmoor/Windisch 
Fig. 3. Correlation analysis of the pressuretime index of the respiratory muscles $\left(\mathrm{PTI}_{\text {mus }}\right)$ with the Quality-of-Life (QoL) item "physical functioning."
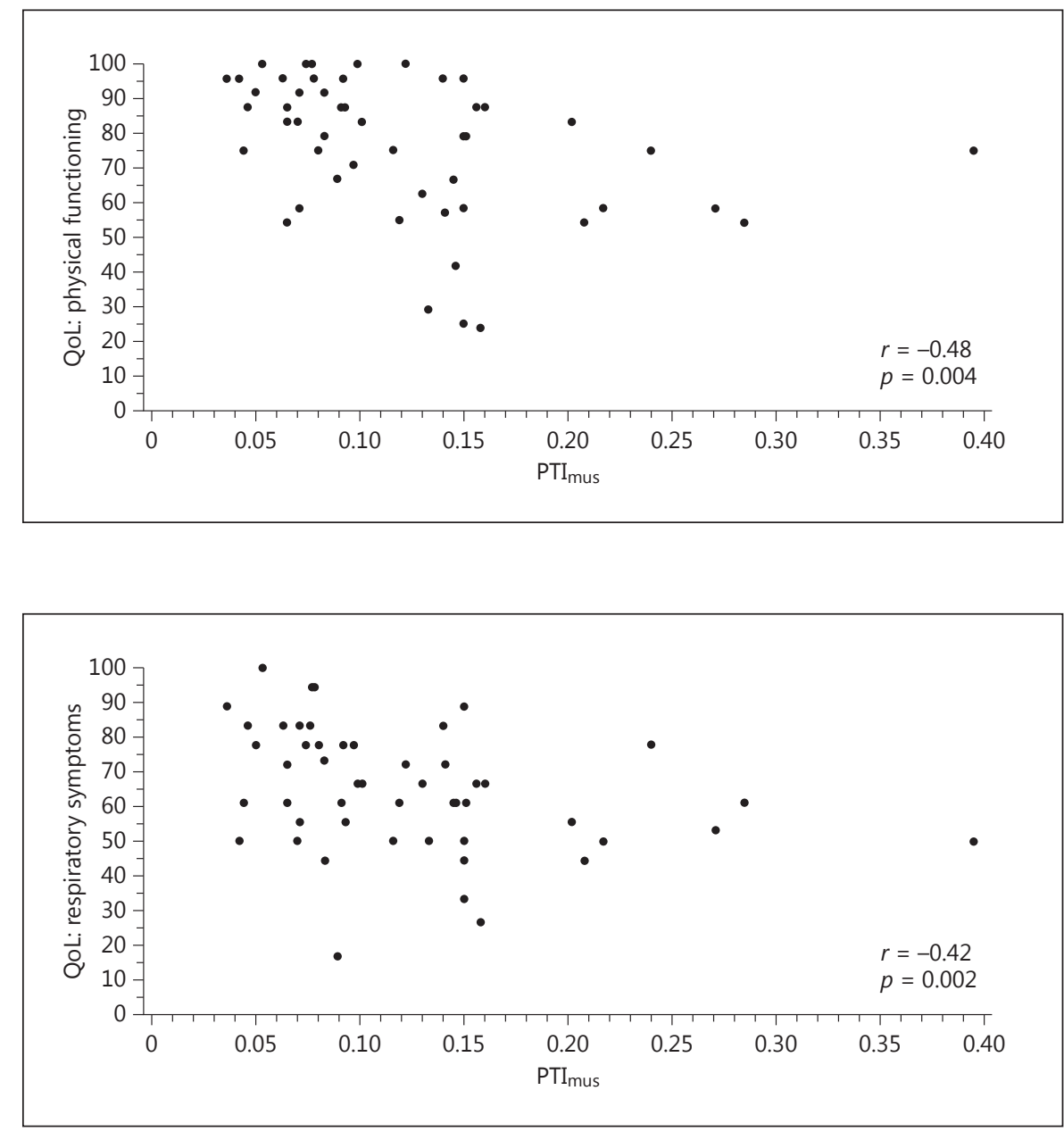

Fig. 4. Correlation analysis of the pressuretime index of the respiratory muscles $\left(\mathrm{PTI}_{\text {mus }}\right)$ with the Quality-of-Life (QoL) item "respiratory symptoms."

Table 4. Quality-of-Life data (CFQ-R) according to gender

\begin{tabular}{lllrr}
\hline CFQ-R subscale & Male $(n=18)$ & Female $(n=33)$ & \multicolumn{1}{c}{$\begin{array}{l}\text { Difference } \\
\text { of means }\end{array}$} & $95 \%$ CI \\
\hline Physical functioning & $89.6(79.2-95.8)$ & $75.0(58.3-87.5)$ & 12.1 & 0.52 to 23.60 \\
Respiratory symptoms & $75.6(61.1-83.3)$ & $61.1(50.0-72.2)$ & 12.2 & 2.45 to 22.00 \\
Health perception & $66.7(55.6-100)$ & $66.7(55.6-77.8)$ & 8.2 & -4.33 to 20.65 \\
Treatment burden & $66.7(66.7-88.9)$ & $55.6(44.4-66.7)$ & 12.7 & 0.015 \\
\hline
\end{tabular}

Values are indicated as median (and IQR). CRQ-R, Cystic Fibrosis Questionnaire-Revised; CI, confidence interval; IQR, interquartile range.

\section{Secondary Outcome Parameters}

There were no differences between groups (A vs. B and $\mathrm{C}$ vs. D) when the following measures were compared: $\mathrm{P}_{0.1}, \mathrm{PI}_{\max }, \mathrm{PE}_{\max }, \mathrm{P}_{0.1} / \mathrm{PI}_{\max }, \mathrm{P}_{0.1} \times \mathrm{T}_{\mathrm{I}} / \mathrm{TV}$, the QoL items "physical functioning" and "respiratory symptoms," BMI, $\mathrm{FEV}_{1}$ (\%pred.), IVC (\%pred.), TLC (\%pred.), RV (\%pred.), and walking distance (m). Regarding $\mathrm{Sn}_{\mathrm{Pna}}$, the difference was 1.54 (95\% CI $[-0.04,3.12] ; p=0.056)$ for group B versus group A and 1.69 (95\% CI [0.20, 3.19]; $p=0.027$ ) for group $\mathrm{D}$ versus group $\mathrm{C}$. $\mathrm{PI}_{\max }$ was $89.5 \%$ in all CF patients compared to the 50th (median) percentiles of age-related normal values in healthy subjects [14]. 
An analysis of the correlation of the $\mathrm{PTI}_{\text {mus }}$ and QoL subdomains with respiratory muscle function parameters, lung function, and exercise capacity is displayed in Table 3. In summary, $\mathrm{PTI}_{\text {mus }}$ was positively correlated with parameters of the load imposed on the respiratory muscles. In contrast, $\mathrm{PTI}_{\text {mus }}$ was negatively correlated with the parameters of inspiratory muscle strength and QoL (Fig. 3, 4). Male patients had a better QoL than female patients (Table 4).

\section{Discussion}

This is the first study to evaluate respiratory muscle function in adult CF patients in relation to $P$. aeruginosa infection status. By comparing $\mathrm{PTI}_{\text {mus }}$ measurements in CF patients with or without $P$. aeruginosa infection, the main finding of the present study was that there was no significant difference in the efficiency as well as the function of respiratory muscles between these 2 groups. In addition, neither the load imposed on the respiratory muscles nor the maximum inspiratory muscle strength was impaired in patients with $P$. aeruginosa infection compared to those without. In contrast, patients chronically infected with $P$. aeruginosa had greater diaphragmatic muscle strength than those patients who were not chronically infected.

The findings of the present study are in clear contrast to those of Dassios et al. [7], who investigated respiratory muscle function in adolescent CF patients according to $P$. aeruginosa infection status. Of note, that study used the same primary outcome as the present study - namely, $\mathrm{PTI}_{\text {mus }}$ measurement - and has been the only study to date to investigate respiratory muscle function in CF patients with respect to their $P$. aeruginosa infection status. The present report, therefore, demonstrates that the findings described for adolescent CF patients cannot be extrapolated to adult CF patients. For example, respiratory muscle efficiency was shown to be significantly impaired in adolescent CF patients with chronic $P$. aeruginosa infection, while it remained unaffected in the adult CF patients [7]. Similarly, $\mathrm{PI}_{\max }$ measurements showed that chronic $P$. aeruginosa infection led to an impairment of global respiratory muscle strength in adolescents, whereas in adults it did not. Furthermore, diaphragmatic strength was found to be rather greater in chronically affected adult patients. Increased respiratory muscle strength has previously been attributed to a training effect that is related to the increased work of breathing [30]; this is also true for chronic P. aeruginosa infection. However, there are conflicting results regarding respiratory muscle strength in the literature [30-33], and this issue needs to be elucidated in the future.

The reasons for these discrepancies between study findings remain unclear, but they seem to be complex. One possible explanation is that respiratory muscle function in older patients with a longer history of CF, more co-morbidities, other treatment strategies, or additional respiratory affection is influenced by more than just $P$. aeruginosa infection alone. In this regard, the present study provided detailed information on the presence of other pathogens, showing that most of the patients had multiple co-infections. Importantly, such information was omitted from the study by Dassios et al. [7], where infection with pathogens other than $P$. aeruginosa (with the exception of Haemophilus influenzae and S. aureus) led to exclusion from the study.

Importantly, the respiratory muscle function parameters showed broad variability, particularly in the case of efficiency, load, and strength. In addition, respiratory muscle function was more efficient in male than in female patients. This could be explained by the greater global inspiratory muscle strength in males [14], which is included in the calculation of the $\mathrm{PTI}_{\text {mus }}$. Correspondingly, male patients showed a higher QoL than female patients.

In addition, some patients were hyperinflated, and this could also have led to an impairment of respiratory muscle strength, as has previously been shown in patients with CF [31]. However, the degree of hyperinflation was mild, and only severe hyperinflation as defined by an RV/ TLC ratio $>50 \%$ was shown to be associated with impaired respiratory muscle strength [31]. Moreover, there was no clear difference between the subgroups of patients regarding the degree of hyperinflation.

However, other conditions predisposing respiratory muscle function to impairment remain unclear. To this end, the present study showed that reduced efficiency of the respiratory muscles was associated with reduced QoL. In addition, QoL was suggested to be lower in patients never infected with $P$. aeruginosa, even though the opposite could have been expected. The reason for this, however, remains unclear. Therefore, future studies should investigate the additional factors contributing to respiratory muscle dysfunction and QoL.

There are some limitations of the study that need to be addressed. Firstly, this was a single-centre study; therefore, recruitment of patients was restricted to the group forming the outpatient pool at the CF centre. Even though the target sample size was reached, the 4
Magnet/Callegari/Dieninghoff/ Spielmanns/Storre/Schmoor/Windisch 
groups of patients formed according to their $P$. aeruginosa status were not equally distributed. In particular, it was difficult to find adult patients who were purely $P$. aeruginosa negative. This was completely different to the above-cited study on adolescents [7]. Secondly, many patients had co-infections with other specimens, which was not avoidable in the current adult population. Nevertheless, the impact of $P$. aeruginosa on respiratory muscle function may be misconstrued due to other pathogens contributing to changes in respiratory mechanics. Thirdly, as in all the other studies, respiratory muscle strength was measured by volitional tests, which extensively depend on participants making a truly maximal effort. However, reliable measurements would require non-volitional tests; therefore, this needs to be addressed in future studies.
In conclusion, chronic $P$. aeruginosa infection does not have an impact on respiratory muscle efficiency in adult CF patients with otherwise multiple co-infections with different specimens typical of this collective. However, respiratory muscle function was heterogeneous amongst the different CF individuals, and those CF patients with reduced respiratory muscle efficiency had worse QoL.

\section{Acknowledgements}

All participants are acknowledged for the effort they devoted to this study, and Dr. Sandra Dieni for proofreading the manuscript.

\section{References}

1 Dodge JA, Lewis PA, Stanton M, Wilsher J: Cystic fibrosis mortality and survival in the UK: 1947-2003. Eur Respir J 2007;29:522526.

2 Bodnar R, Kadar L, Holics K, Ujhelyi R, Kovacs $\mathrm{L}$, Bolbas $\mathrm{K}$, et al: Factors influencing quality of life and disease severity in Hungarian children and young adults with cystic fibrosis. Ital J Pediatr 2014;40:50.

-3 Emerson J, Rosenfeld M, McNamara S, Ramsey B, Gibson RL: Pseudomonas aeruginosa and other predictors of mortality and morbidity in young children with cystic fibrosis. Pediatr Pulmonol 2002;34:91-100.

-4 Sordé R, Pahissa A, Rello J: Management of refractory Pseudomonas aeruginosa infection in cystic fibrosis. Infect Drug Resist 2011;4:31-41.

5 van de Weert-van Leeuwen PB, Slieker MG, Hulzebos HJ, Kruitwagen CL, van der Ent CK, Arets HG: Chronic infection and inflammation affect exercise capacity in cystic fibrosis. Eur Respir J 2012;39:893-898.

6 Burtin C, Hebestreit H: Rehabilitation in patients with chronic respiratory disease other than chronic obstructive pulmonary disease: exercise and physical activity interventions in cystic fibrosis and non-cystic fibrosis bronchiectasis. Respiration 2015;89:181-189.

7 Dassios TG, Katelari A, Doudounakis S, Dimitriou G: Chronic Pseudomonas aeruginosa infection and respiratory muscle impairment in cystic fibrosis. Respir Care 2014;59:363-370.

8 Reid MB, Lännergren J, Westerblad H: Respiratory and limb muscle weakness induced by tumor necrosis factor- $\alpha$ : involvement of muscle myofilaments. Am J Respir Crit Care Med 2002;166:479-484.
-9 Divangahi M, Balghi H, Danialou G, Comtois AS, Demoule A, Ernest S, et al: Lack of CFTR in skeletal muscle predisposes to muscle wasting and diaphragm muscle pump failure in cystic fibrosis mice. PLoS Genet 2009;5: e1000586.

10 Farrell PM, Rosenstein BJ, White TB, Accurso FJ, Castellani C, Cutting GR, et al: Guidelines for diagnosis of cystic fibrosis in newborns through older adults: Cystic Fibrosis Foundation consensus report. J Pediatr 2008;153:S4S14.

11 Bilton D, Canny G, Conway S, Dumcius S, Hjelte L, Proesmans M, et al: Pulmonary exacerbation: towards a definition for use in clinical trials. Report from the EuroCareCF Working Group on outcome parameters in clinical trials. J Cyst Fibros 2011;10(suppl 2): S79-S81.

12 Kabitz HJ, Walterspacher S, Mellies U, Criée $\mathrm{CP}$, Windisch W: Recommendations for respiratory muscle testing (in German). Pneumologie 2014;68:307-314.

13 American Thoracic Society/European Respiratory Society: ATS/ERS Statement on respiratory muscle testing. Am J Respir Crit Care Med 2002;166:518-624.

14 Windisch W, Hennings E, Sorichter S, Hamm $\mathrm{H}$, Criée CP: Peak or plateau maximal inspiratory mouth pressure: which is best? Eur Respir J 2004;23:708-713.

15 Hayot M, Guillaumont S, Ramonatxo M, Voisin M, Préfaut C: Determinants of the tension-time index of inspiratory muscles in children with cystic fibrosis. Pediatr Pulmonol 1997;23:336-343.
16 Ramonatxo M, Boulard P, Préfaut C: Validation of a noninvasive tension-time index of inspiratory muscles. J Appl Physiol (1985) 1995;78:646-653.

17 Gaultier C: Tension-time index of inspiratory muscles in children. Pediatr Pulmonol 1997; 23:327-329.

18 Miller MR, Crapo R, Hankinson J, Brusasco V, Burgos F, Casaburi R, et al: General considerations for lung function testing. Eur Respir J 2005;26:153-161.

19 Macintyre N, Crapo RO, Viegi G, Johnson DC, van der Grinten CP, Brusasco V, et al: Standardisation of the single-breath determination of carbon monoxide uptake in the lung. Eur Respir J 2005;26:720-735.

20 Wanger J, Clausen JL, Coates A, Pedersen OF, Brusasco V, Burgos F, et al: Standardisation of the measurement of lung volumes. Eur Respir J 2005;26:511-522.

21 Pellegrino R, Viegi G, Brusasco V, Crapo RO, Burgos F, Casaburi R, et al: Interpretative strategies for lung function tests. Eur Respir J 2005;26:948-968.

22 Miller MR, Hankinson J, Brusasco V, Burgos F, Casaburi R, Coates A, et al. Standardisation of spirometry. Eur Respir J 2005;26:319-338.

23 Hebestreit H, Arets HG, Aurora P, Boas S, Cerny F, Hulzebos EH, et al: Statement on exercise testing in cystic fibrosis. Respiration 2015;90:332-351.

24 ATS Committee on Proficiency Standards for Clinical Pulmonary Function Laboratories: ATS statement: guidelines for the six-minute walk test. Am J Respir Crit Care Med 2002; 166:111-117. 
25 Dreher M, Storre JH, Windisch W: Noninvasive ventilation during walking in patients with severe COPD: a randomised cross-over trial. Eur Respir J 2007;29:930-936.

-26 Quittner AL, Buu A, Messer MA, Modi AC, Watrous M: Development and validation of the Cystic Fibrosis Questionnaire in the United States: a health-related quality-of-life measure for cystic fibrosis. Chest 2005; 128:23472354.

-27 Quittner AL, Sawicki GS, McMullen A, Rasouliyan L, Pasta DJ, Yegin A, et al: Erratum to: Psychometric evaluation of the Cystic Fibrosis Questionnaire-Revised in a national, US sample. Qual Life Res 2012;21:1279-1290.
28 Pressler T, Bohmova C, Conway S, Dumcius S, Hjelte L, Høiby N, et al: Chronic Pseudomonas aeruginosa infection definition: EuroCareCF Working Group report. J Cyst Fibros 2011;10(suppl 2):S75-S78.

29 Lee TW, Brownlee KG, Conway SP, Denton M, Littlewood JM: Evaluation of a new definition for chronic Pseudomonas aeruginosa infection in cystic fibrosis patients. J Cyst Fibros 2003;2:29-34.

30 Dunnink MA, Doeleman WR, Trappenburg JC, de Vries WR: Respiratory muscle strength in stable adolescent and adult patients with cystic fibrosis. J Cyst Fibros 2009;8:31-36.
31 Szeinberg A, England S, Mindorff C, Fraser IM, Levison H: Maximal inspiratory and expiratory pressures are reduced in hyperinflated, malnourished, young adult male patients with cystic fibrosis. Am Rev Respir Dis 1985;132:766-769.

32 Chatham K BS, Beeson C, et al: Inspiratory pressures in adult cystic fibrosis. Physiotherapy 1994,80:748-752.

33 Reilly CC, Ward K, Jolley CJ, Lunt AC, Steier J, Elston C, et al: Neural respiratory drive, pulmonary mechanics and breathlessness in patients with cystic fibrosis. Thorax 2011;66: 240-246. 